\title{
Dinamika Pendidikan Karakter dalam Kajian Budaya Dan Psikologi Pendidikan
}

\section{The Dynamics of Character Education in Cultural Studies and Educational Psychology Sihar Pandapotan}

\author{
UPBJJ Universitas Terbuka Medan, Indonesia
}

Diterima: Agustus 2019; Disetujui: Desember 2019; Dipublish: Desember 2019

*Coresponding Email: khairat2019@gmail.com

\section{Abstrak}

Indonesia memberikan fokus perhatian yang tinggi pada aspek pendidikan. Hal ini terlihat dari sistem pendidikan yang selalu diperbaharui guna mengikuti perkembangan zaman. setiap Namun beberapa realitas sosial di Indonesia hari ini menunjukkan di sisi lain krisis moral juga semakin meningkat. Hal ini tentu menjadi sebuah kepincangan dalam dunia pendidikan terutama dalam pendidikan karakter yang digadang-gadang sebagai gagasan yang mampu menciptakan karakter nasional indonesia. Perjalanan pendidikan karakter yang seharusnya diharapkan mampu meminimalisir krisis moral namun masih diabaikan. Pendidikan karakter dianggap hanya menjadi tugas dunia sekolah saja, padahal sebenarnya lingkungan sosial juga berperan sangat penting dalam membantu melaksanakan pendidikan karakter di masyarakat. Inilah yang menjadi dinamika dalam pendidikan karakter dewasa ini. Padahal pendidikan karakter sebenarnya telah dilakukan oleh para nenek moyang kita terdahulu dan telah diwariskan secara turun temurun melalui pepatah hidup, norma dan adat istiadat yang dalam kajian budaya dikenal dengan istilah Folklore. Sebuah warisan budaya berbentuk lisan, tulisan, maupun gerak ini mampu memberikan penanaman moral dan pendidikan karakter. Metode penelitian dalam tulisan ini adalah dengan bentuk metode studi literatur. Menelisik dan menelaah dinamika pendidikan karakter dari hasil tulisan terdahulu yang berfokus pada kajian budaya dan psikologi pendidikan

Kata Kunci: Pendidikan karakter, budaya, Folklore

\begin{abstract}
Indonesia focuses high attention on the educational aspect. This can be seen from the education system that is always being updated to keep up with the times. However, several social realities in Indonesia today show that on the other hand the moral crisis is also increasing. This certainly becomes a lameness in the world of education, especially in character education which is predicted as an idea that is able to create Indonesian national character. The journey of character education should be expected to be able to minimize the moral crisis but is still ignored. Character education is considered to be only the task of the school world, when in fact the social environment also plays a very important role in helping carry out character education in society. This is the dynamic in character education today. Whereas character education has actually been carried out by our forefathers and has been passed down through generations through the proverbial life, norms and customs which in cultural studies are known as Folklore. A cultural heritage in the form of oral, written, and movement is able to provide moral cultivation and character education. The research method in this paper is a form of literature study method. Examining and analyzing the dynamics of character education from the results of previous writings that focus on the study of cultural and educational psychology.
\end{abstract}

Keywords: Character Education, Culture, Folklore

How to Cite: Pandapotan, S. (2019). Dinamika Pendidikan Karakter dalam Kajian Budaya Dan Psikologi Pendidikan. Journal of Education, Humaniora and Social Sciences (JEHSS). 2 (2): 271-278. 


\section{PENDAHULUAN}

Pendidikan adalah hal yang paling mendasar dan sangat berperan penting dalam pengembangan diri keilmuan dan karakter individu itu sendiri. Hal ini dijelaskan dalam tujuan dari pendidikan yang tertera dalam Bab II pasal 3 RI No.20 Tahun 2003 tentang system pendidikan Nasional dijelaskan bahwa tujuan pendidikan Nasional adalah mengembangkan potensi peserta didik agar menjadi manusia yang beriman dan bertakwa kepada Tuhan yang Maha Esa, berakhlak mulia, sehat, berilmu, cakap, kreatif, mandiri, dan menjadi warga Negara yang demokratis dan bertanggung jawab.

Pada tujuan pendidikan nasional yang tertera ini kita dapat melihat bagaimana pendidikan Nasional menginginkan agar pendidikan itu sejatinya mampu membentuk peserta didik yang tidak hanya menjadi individu yang cerdas dalam inteligensi saja, akan tetapi juga cerdas dalam sikap maupun karakter yang lebih baik. Namun pada saat sekarang ini realitas sosial yang kita lihat adalah peningkatan sisi inteligensi memang telah sangat baik namun pada karakter individu masih menjadi pekerjaan rumah yang cukup besar yang harus segera ditangani oleh seluruh lapisan masyarakat di Indonesia.

Hasil penelitian yang dilakukan oleh Badan Koordinasi Keluarga Berencana Nasional (BKKBN) dibeberapa kota besar di Indonesia seperti Jabotabek, Surabaya, Bandung, dan Medan pada tahun 2018 menunjukkan bahwa data remaja yang pernah melakukan free sex telah mencapai 50\% dan melakukan aborsi sebanyak 21\%, Dan ini dilakukan pada umur 13 hingga 18 tahun, (Tribun. 25 Desember 2018).

Sebuah data yang menunjukkan betapa menyedihkannya kondisi moral pada generasi muda di Indonesia ditengah penggadang-gadangan gagasan pendidikan karakter di dalam kurikulum pendidikan Indonesia. Seluruh lapisan masyarakat baik yang berkecimpung dalam dunia pendidikan maupun yang tidak diharapkan dapat berperan aktif menjadi pengontrol sosial dengan konsep penanaman pendidikan karakter yang di desain oleh pemerintah.

Menurut Kesuma (2017) bahwa pendidikan karakter di sekolah adalah inti penting dalam setiap unsur sistem belajar mengajar yang terlaksana. Sebuah pembelajaran yang tanpa diisi oleh unsur pendidikan karakter didalamnya sama saja dianggap bukan merupakan sebuah proses belajar mengajar yang baik. Maka dari itu diperlukan adanya sebuah perhatian khusus dalam pembelajaran agar terjadinya penguatan karakter pada siswa yang muaranya adalah siswa secara sadar mampu membentengi dirinya dalam 
pergaulan yang negative dan membawa pada masalah social (Matondang, Lubis \& Suharyanto, 2018; Andayani, Puspitawati, Juliarti, 2018)

Begitu banyaknya realitas yang terjadi hari ini menunjukkan dengan gamblang bagaimana keadaan sosial para generasi muda yang telah mengalami degradasi moral, namun sebenarnya menjadi sebuah tanda tanya besar disaat begitu banyaknya juga warisan budaya leluhur berbagai macam suku yang mendiami wilayah Indonesia dan merupakan sebuah bentuk proses pendidikan karakter. Dengan pola kehidupannya yang tradisional dan sarat akan adat istiadat, banyak suku yang secara langsung telah mengimplementasikan proses pendidikan karakter dengan sistem kolektif masyarakatnya. Falsafah hidup, pandagan hidup, petuah, sistem kekerabatan, norma dan adat istiadat yang terinpretasi sebagai proses pendidikan karakter yang dilakukan dengan bentuk tradisi lisan maupun non lisan yang dikenal dengan istilah Folklore. Folklore berisikan begitu banyak makna dan tuntunan hidup yang mampu membentengi para anak muda suku tersebut dalam menjaga perilaku. Inilah yang menjadi landasan tulisan yang ingin melihat bagaimana pendidikan karakter tersebut dalam lingkup kajian budaya (Syukria \& Siregar, 2018; Sundari, Ernata, Nurmi \& Ekomila, 2017; Ramdani, 2018)..

\section{PEMBAHASAN}

Pendidikan dalam bentuk pengarahan adalah upaya atau tindakan pendidikan yang lebih terfokus pada membantu pengembangan domain afektif, seperti pengembangan nilai, sikap, motivasi, emosi, apresiasi dan lain-lain. Hal ini sangatlah berperan penting dalam pengembangan karakter. Istilah karakter sudah sangat sering kita dengar seharihari. Karakter secara terminology dalam Kamus Bahasa Indonesia memiliki arti watak, sikap kepribadian dan tindakan emosional individu. Dalam kajian Budaya, istilah karakter lebih dikenal dengan sebutan kepribadian (personality).

Morton (Meutia, 2008) menjelaskan bahwa "Kepribadian adalah kumpulan pembawaan biologis berupa dorongan, kecenderungan, selera, dan instink yang dicampuri dengan sifat dan kecenderungan yang didapat melalui pengalaman yang terdapat pada diri seseorang". Morton dalam definisinya lebih melihat pada factor pembawaan biologis yang dimiliki oleh setiap individu yang pastinya juga akan mempengaruhi karakter ataupun kepribadian dirinya. Hal ini tidaklah salah, karena 
didalam ilmu psikologi hal ini dikatakan sebagai factor endogen yakni sifat yang dibawa oleh individu dari kandungan hingga kelahiran.

Sedangkan menurut Allport (Meutia, 2008), kepribadian adalah organisasi dinamis dalam diri individu yang terdiri dari system psiko-fisik yang menentukan cara penyesuaian diri yang unik (khusus) dari individu tersebut terhadap lingkungannya". Allport sendiri lebih memandang bahwa kepribadian adalah sebuah strukutur yang bukanlah bersifat statis (tetap,) tetapi juga dapat berubah tergantung dari pengalaman yang individu tersebut dapatkan. Pengalaman yang bersifat umum serta pengalaman yang bersifat khusus.

Pengalaman umum yaitu yang dialami oleh tiap-tiap individu dalam pola-pola kebudayaan tertentu. Pengaruh pola-pola kebudayaan terhadap seseorang tidaklah sama karena medianya (orangtua, saudara, lingkungan, dan lain-lainnya) tidaklah sama pula pada setiap individu. Setiap orangtua memiliki kebudayaan yang berbeda dalam memberikan pengajaran. Berbeda cara, berbeda pandangan, serta berbeda prinsip. Begitu pula dengan lingkungan. Kebudayaan yang dihasilkan dari masing-masing lingkungan yang berbeda juga akan memberikan perbedaan pengaruh baik pada psiko dan fisik individu tersebut.

Sedangkan pengalaman khusus yaitu yang memang khusus dialami individu sendiri. Pengalaman ini tidak tergantung pada status dan peranan orang yang bersangkutan dalam masyarakat. Seperti contoh pengalaman seseorang terhadap pekerjaan yang pernah dia lakukan.

Pada kajian Psikologi Pendidikan Terdapat beberapa hal penting berkaitan dengan fase perkembangan anak sebelum dilakukannya pendidikan karakter. Hal ini bermanfaat dalam mempermudah kita melakukan pendidikan karakter. Fase-fase yang berbeda dalam tahap perkembangan anak menginformasikan dan membuat kita mengetahui metode dan cara yang tepat dalam membimbing dan melakukan pendidikan kepribadian kepada si anak. Papalia dan Old (Reni, 2001) membagi masa kanak-kanak dalam lima tahap: 1) Masa Prenatal, yaitu diawali dari masa konsepsi sampai masa lahir; 2) Masa bayi dan tatih, yaitu saat usia 18 bulan pertama kehidupan, merupakan masa bayi. Di atas usia 18 bulan sampai dengan tiga tahun merupakan masa tatih. Saat tatih inilah, anak-anak menuju pada penguasaan bahasa dan motorik serta kemandirian; 3) Masa kanak-kanak pertama, yaitu rentang usia 3-5 tahun; 4) Masa kanak-kanak kedua, yaitu 
usia 5-12 tahun, dikenal sebagai masa pra sekolah dan masa sekolah. Anak-anak telah mampu menerima pendidikan formal dan menyerap berbagai hal yang ada dilingkungannya; 5) Masa remaja, yaitu rentang usia 12-18 tahun. Saat anak mencari identitas dirinya dan banyak menghabiskan waktunya dengan teman sebayanya serta berupaya lepas dari lingkungan orang tua

Menurut Papalia dan Old, (Hawadi, 2001), masa kanak-kanak kedua adalah masa yang paling tepat dalam memberikan bimbingan yang berfokus pada kepribadian anak. Karena pada fase ini anak sangat rentan dalam menerima pemahaman akan kebenaran suatu yang baik dan suatu yang tidak baik. Hal ini juga dibenarkan oleh Freud. Menurut Freud, (Meutia, 2008) perkembangan kepribadian seseorang sudah terbentuk pada akhir tahun kelima umurnya dan perkembangan selanjutnya sebahagian besar hanya penghalusan dan penambahan strukutur dasar yang sudah terbentuk.

Pendidikan kepribadian sendiri sebenarnya sudah lama diterapkan oleh dan dilakukan banyak suku di Indonesia. Penanaman nilai-nilai moral dilakukan secara turun temurun baik dengan cara yang bersifat lisan maupun tulisan. Didalam kajian budaya, pendidikan kepribadian yang dilakukan oleh para leluhur suku-suku tersebut diakomidir oleh hasil budaya yang disebut dengan tradisi lisan atau yang dikenal dengan istilah Folklore.

Folklor adalah pengindonesiaan kata inggris folklore. Menurut Alan Dundes, (Danandjaja, 2005) folklore adalah bahagian dari kebudayaan yang tersebar dan diwariskan secara turun-temurun. Baik dalam bentuk lisan ataupun contoh yang disertai dengan gerak isyarat. Jan Harold Barunvand (Danandjaja, 2005) seorang ahli folklore dari Amerika menjelaskan bahwa folklore di Indonesia tergolongkan dalam tiga kelompok yaitu:

1. folklore lisan adalah folklore yang bentuknya memang murni Lisan. Bentuk-bentuk ( genre ) folklore yang termasuk kedalam kelompok besar ini antara lain adalah

a. bahasa rakyat seperti logat, julukan, pangkat tradisional, dan title kebangsawanan

b. ungkapan tradisional seperti pribahasa, dan pepatah

c. pertanyaan tradisional seperti teka-teki,

d. puisi rakyat seperti pantun, gurindam dan syair

e. cerita prosa rakyat seperti mitos, legenda, dan dongeng

f. nyanyian rakyat 


\section{Folklore sebagai lisan}

Adalah bentuknya merupakan campuran unsure lisan dan unsure bukan lisan. Kepercayaan rakyat, misalnya yang oleh orang "moderen" seringkali disebut dengan takhayul. Bentuk-bentuk folklore yang tergolong dalam kelompok ini selain kepercayaan rakyat adalah permainan rakyat, teater rakyat, tari rakyat, pesta rakyat dan lain-lain

3. Folklore bukan lisan

Adalah folklore yang bentuknya bukan lisan, walaupun demikian cara pembuatannya diajarkan lisan dan memiliki makna. Dalam kelompok ini banyak tergolong material. Contohnya adalah rumah adapt, pakaian adapt, makanan dan minuman rakyat, obat-obatan tradisional, dan bunyi isyarat untuk komunikasi rakyat.

Di dalam beberapa contoh folklore sebenarnya banyak sekali pendidikan kepribadian yang ditanamkan secara berkesinambungan baik dalam pepatah hidup, norma, adat istiadat. Salah satu bentuk media yang paling tepat adalah Dongeng yang merupakan bagian dari Folklore tersebut. Dongeng adalah produk budaya yang sangat tepat dengan fase perkembangan anak. Terutama pada fase kanak-kanak pertama dan fase kanak-kanak kedua.

Banyak sekali contoh-contoh dongeng yang dapat dijadikan penanaman nilai-nilai moral dan kepribadian. Sebagai contoh legenda Danau Toba pada Etnik Batak Toba yang menanamkan nilai moral dalam menjaga amanah. Simalin Kundang anak Durhaka pada etnik Minangkabau yang memberikan penanaman nilai rasa hormat pada orangtua. Penanaman nilai sikap sombong yang tidak baik pada cerita si Kelinci dan kura-kura.

Menurut Zakia (2017) dongeng memiliki beberapa manfaat bagi anak. Diantaranya adalah: 1) Mengajarkan budi pekerti; 2) Membiasakan budaya membaca; 3) Mengembangkan imajinasi anak

Pada bagian pengembangan imajinasi anak, penanaman budi pekerti dapat terjadi dengan baik. Penanaman karakter lainnya juga dapat dilakukan. Hal ini dikarenakan fase berfikir anak yang masih sering mengingat perilaku baik dan buruk dengan bentuk imajinasi. Sehingga ketika mengingat kepribadian menjaga amanah, anak akan mudah mengingat legenda danau Toba tentang pentingnya menjaga janji dan amanah.

Tidak hanya itu saja, bentuk folklore lainnya juga dapat membantu upaya Pendidikan kepribadian ini. Seperti pada folklore non lisan yaitu permainan tradisional. Hasil penelitian Sudrajat (2015) memaparkan bahwa permainan tradisional 
menanamkan karakter sportivitas, kesetiakawanan, dan kerjasama pada anak dan masih banyak lagi contoh lainnya yang juga memberikan pendidikan kepribadian.

Pendidikan kepribadian yang telah dilakukan oleh para nenek moyang secara turun-temurun melalui folklore ini menunjukkan bahwa sebenarnya pendidikan kepribadian sangatlah mudah dilakukan dan bisa dilakukan dimana saja tanpa terkait keadaan yang formal, bahkan pendidikan karakter telah dimulai dalam pendidikan non formal dikeluarga dan lingkungan sosial masyarakatnya. cukup dengan hanya membutuhkan pendekatan kekeluargaan yang sangat kental dalam mendidiknya.

Maka dari itu, dalam melakukan pendidikan kepribadian kepada anak, metode folklore dapat menjadi sebuah metode yang sangat tepat. Apalagi metode folklore ini sangat cocok dilakukan pada masa kanak-kanak kedua yakni disaat anak usia 5-12 tahun, yang oleh Papalia dan Old disebut sebagai fase yang tepat bagi anak dalam menerima penanaman nilai-nilai, moral dan sikap yang terkandung dalam folklore tersebut seperti contoh cerita rakyat yang kita ceritakan. Ditambah lagi pada fase ini dalam ilmu psikologi anak masih senang bermain, maka kita juga dapat memberikannya pembelajaran sambil bermain. Pembelajaran yang menanamkan nilai-nilai kepribadian seperti permainan rakyat.

\section{SIMPULAN}

Dinamika pendidikan karakter tidak terlepas dari keadaan degradasinya moral masyarakat. Namun dalam kajian Budaya, Dongeng yang merupakkan bagian dari Folklore dapat memberikan sumbangsih dalam dinamika pendidikan karakter. Indonesia dengan keberagaman suku dan warisan budayanya juga memiliki begitu banyak jenisjenis Folklore yang berguna sebagai media dalam penanaman pendidikan karakter. Baik dalam bentuk pepatah, cerita rakyat, norma, adat istiadat dan lain sebagainya yang ternyata menjadi sebuah bentuk pendidikan karakter yang telah ada sejak dahulu dan dapat diterapkan disaat sekarang. Pendidikan karakter dalam telaah psikologi pendidikan, tentunya juga perlu melihat aspek, fase dan karakter kepribadian pada anak sehingga akan mempermudah pendidikan karakter itu sendiri.

\section{DAFTAR PUSTAKA}

Ahmadi, A. (1992). Psikologi Umum. Rineka Cipta: Jakarta 
Andayani, T., Puspitawati, Juliarti (2018), Upaya Menebarkan Nilai-Nilai Kebaikan melalui Pelatihan Mendongeng bagi Siswa/i Sekolah Dasar di Kecamatan Percut Sei Tuan, Anthropos: Jurnal Antropologi Sosial dan Budaya (Journal of Social and Cultural Anthropology), 3 (2): 61-68

Danandjaja, J. (2005). Folklore Indonesia. Grafiti Pers: Jakarta

Danandjaja, J. (2008). Antropologi Psikologi. Rajawali Pers: Jakarta

Habsari Z. (2017). Dongeng Sebagai Pembentuk Karakter Anak. Jurnal Kajian perpusatakaan dan informasi BIBLIOTIKA

Kesuma, D. dkk. (2017). Pendidikan Karakter Kajian Teori dan Praktik di Sekolah. Bandung: Rosda

Matondang, A., Lubis, Y.A., \& Suharyanto, A., (2018), Eksistensi Budaya Lokal dalam Usaha Pembangunan Karakter Siswa SMP Kota Padang Sidimpuan, Anthropos: Jurnal Antropologi Sosial dan Budaya (Journal of Social and Cultural Anthropology), 3 (2): 103-116

Meutia, C. (2008). Psikologi Kepribadian. Mutiara: Medan

Ramdani, E. (2018). Model Pembelajaran Kontekstual Berbasis Kearifan Lokal sebagai Penguatan Pendidikan Karakter, JUPIIS: Jurnal Pendidikan Ilmu-Ilmu Sosial, 10 (1): 1-10.

Sanjaya W. (2017. Strategi Pembelajaran Berorientasi Standar Proses Pendidikan. 2017: Kencana.

Sudrajat, dkk. (2015). Muatan Nilai-Nilai Karakter Melalui Permainan Tradisional di PAUD Among Siwi Bantul. JIPSINDO No 1 Volume2

Sundari, F., Ernata S., Nurmi R., dan Sulian E., (2017). Penerapan Program FOS (Folktale Speaking) sebagai Pembentuk Karakter Anak Usia Dini, JUPIIS: Jurnal Pendidikan Ilmu-Ilmu Sosial, 9 (1): 102-111.

Syamsul A.B. (2015). Psikologi Sosial. Bandung: CV Pustaka Setia

Syukria \& Siregar, N.S.S. (2018). Buku Cerita Si Kancil dan Perilaku Meniru Siswa Taman Kanak-kanak. Gondang: Jurnal Seni dan Budaya, 2 (2): 90-102.

Thontowi, A. (1991). Psikologi Pendidikan. Angkasa: Bandung 